\title{
Alcohol Drinking Patterns and Nutrition in Alcoholic Liver Disease
}

\author{
Sabine Wagnerberger, Giridhar Kanuri and Ina Bergheim \\ Universität Hohenheim
}

Germany

\section{Introduction}

In most Western countries alcoholic beverages contribute markedly to the overall caloric intake. Indeed, alcohol contributes to approximately $5 \%$ of the daily caloric intake in the American diet (Halsted, 2004). Alcohol, besides nicotine, is also the most widely used drug in our society, bearing a large potential for addiction but also organ damage and herein particularly liver damage. Chronic alcohol abuse is frequently accompanied with malnutrition with the degree of malnutrition varying not only between the type of alcohol abuse (e.g. binge drinker vs. chronic drinker) but also the degree of liver damage. For practitioners it is important to recognize the various factors contributing to the evolvement of malnutrition in alcoholic patients, as the correction of deficiencies or other strategies to improve nutritional status may have a beneficial effect in the prevention and treatment of alcoholic liver disease. The effects of alcohol ingestion on dietary pattern, nutrient intake and the intermediary metabolism have been investigated in numerous human but also animal studies. In this chapter the role of alcohol as energy source but also the effects of alcohol ingestion on energy metabolism, dietary pattern and micronutrient bioavailability as well as metabolism with special emphasize on the liver and the development of alcoholic liver disease are reviewed. Furthermore, current recommendations for treatment of malnutrition in patients with alcoholic liver disease are summarized.

\section{Alcohol drinking patterns}

When talking about "alcohol drinking", two main patterns have to be distinguished: acute "binge drinking" and "chronic drinking". As reviewed by Zakhari and Li (2007), the impact of the quantity and frequency of alcohol ingestion on alcoholic liver disease becomes more and more important. Indeed, the results of a Danish prospective study with a cohort of 6152 alcohol misusing men and women indicate that periodic drinking leads to a significantly lower relative risk for developing cirrhosis than daily drinking (Kamper-Jorgensen et al. 2004). The Italian Dionysos Study focused on drinking habits as cofactors of risk for alcoholinduced liver damage. The results of this study show that drinking without food and drinking multiple different alcoholic beverages both increase the risk of developing alcoholic liver disease (Bellentani et al. 1997). Furthermore, it has been shown that the metabolic effects of binge drinking and chronic drinking on the liver also markedly differ (for overview see (Zakhari and Li, 2007)). For example, binge drinking may lead to glycogen 
depletion, acidosis and hypoglycemia; whereas chronic drinking results in the development of alcoholic liver damages. The differences between these two alcohol drinking patterns are detailed in the following.

\subsection{Binge drinking}

The World Health Organization (WHO) defines binge drinking as a pattern of heavy drinking that occurs in an extended period, which is usually defined as more than one day of drinking at a time (WHO, 1994). In the United States (US), the National Institute on Alcohol Abuse and Alcoholism defined a more common definition that a "binge" is a pattern of alcohol drinking that brings blood alcohol level to 0.08 gram-percent or above. For a typical adult, the amount of alcohol that has to be ingested to reach these blood alcohol levels is on average equivalent to consuming five or more drinks (men), or four or more drinks (women), in about two hours (National Institute on Alcohol Abuse and Alcoholism, 2007). In contrast, in the United Kingdom binge drinking is defined as the consumption of more than eight drinks in men and more than six drinks in women in a single day (Institute of Alcohol Studies, 2010). In the United States, the prevalence of binge drinking among adults was $15.2 \%$ in 2009 , with the prevalence being two times higher in men than in women (Kanny et al. 2011). This phenomenon can also be observed in most of the European countries, except for England and Ireland. In these two countries binge drinking is found to be particularly prevalent in women (Dantzer et al. 2006). In terms of age, the prevalence of binge drinking decreases, both in the United States and United Kingdom, with increasing age, indicating that the phenomenon "binge drinking" is as an important problem especially in young people (Institute of Alcohol Studies, 2010). In dependence on "drinking cultures" binge drinking occurs more or less in different countries. In Mediterranean culture, alcoholic beverages, especially wine, are consumed on a daily basis as part of meals and mostly in family settings. In contrast, in Northern cultures, drinking is less frequent in everyday life but heavier, typically around weekends (Institute of Alcohol Studies, 2010).

\subsection{Chronic drinking}

In a systemic review, the risks of moderate alcohol consumption have been weighed against its benefits. As a result of comparing the critical endpoints of alcohol intake related to morbidity and mortality, tolerable upper alcohol intake levels have been defined for the German adult population to be 20 to $24 \mathrm{~g}$ alcohol per day for men and 10 to $12 \mathrm{~g}$ alcohol per day for women (Burger et al. 2004). However, it is recommended that if this amount of alcohol is ingested, at least two days per week should be without any alcohol consumption. Exceeding this tolerable alcohol intake level alcohol consumption is classified as a risk factor for numerous organ damages (e.g. liver, pancreas, stomach, gut).

In Germany, the per-capita consumption of pure ethanol was 9.71 in 2009. Furthermore, in $20063.8 \%$ of the German population met the criteria of alcohol abuse and $2.4 \%$ of alcohol dependence in 2006 (Deutsche Hauptstelle für Suchtfragen, DHS, 2006). According to the 2001-2002 National Epidemiologic Survey on Alcohol and related Conditions, $5.8 \%$ of the US adult population meet the criteria for alcohol dependence or alcoholism and $7.1 \%$ meet the criteria for alcohol abuse (for overview see Zakhari and Li, 2007). Despite intense education on the risks associated with alcohol abuse, in industrialized countries in Europe as well as in the United States, the damage of liver and other organs as a consequence of 
chronic alcohol consumption is still an important health problem. Especially, chronic alcohol abuse is one of the most important risk factors for liver damage (Lieber, 1994). The results of previous studies demonstrated the existence of a dose-response relation between alcohol intake and the risk of liver disease (Lelbach, 1975; Day, 1997). As a consequence of alcohol abuse different alcoholic liver disease patterns such as alcohol-caused fatty liver, alcoholic hepatitis, or alcohol-induced cirrhosis can be observed.

\section{Alcohol and energy metabolism}

\subsection{Alcohol and its contribution to energy intake}

For many people regular alcohol consumption is still a part of their daily diet. Raw alcohol and even more so alcoholic beverages are rather energy dense nutrients. Alcoholic beverages primarily consist of water, ethanol, and, depending on the beverage, variable amounts of carbohydrates as well as to a lesser extend proteins, vitamins or minerals (see Table 1).

\begin{tabular}{|c|c|c|c|c|c|c|c|c|c|}
\hline & $\begin{array}{l}\text { Energy } \\
\text { kcal }\end{array}$ & \multicolumn{2}{|c|}{$\begin{array}{l}\text { Protein } \\
\mathrm{g} \quad \mathrm{kcal}\end{array}$} & \multicolumn{2}{|c|}{$\begin{array}{ll}\text { Fat } & \\
\mathrm{g} & \mathrm{kcal}\end{array}$} & \multicolumn{2}{|c|}{$\begin{array}{l}\text { Carbohydrate } \\
\mathrm{g} \quad \text { kcal }\end{array}$} & \multicolumn{2}{|c|}{$\begin{array}{ll}\text { Ethanol } \\
\mathrm{g} & \mathrm{kcal}\end{array}$} \\
\hline Whiskey & 250 & 0.0 & 0.0 & 0.0 & 0.0 & 0.1 & 0.4 & 36 & 252.0 \\
\hline Vodka & 232 & 0.0 & 0.0 & 0.0 & 0.0 & 0.0 & 0.0 & 33.4 & 233.8 \\
\hline $\begin{array}{l}\text { Dry red } \\
\text { wine }\end{array}$ & 60 & 0.7 & 2.9 & 0.0 & 0.0 & 4.6 & 18.9 & 5.5 & 38.5 \\
\hline $\begin{array}{l}\text { Dry white } \\
\text { wine }\end{array}$ & 42 & 0.5 & 2.1 & 0.0 & 0.0 & 3.1 & 12.7 & 4.0 & 28.0 \\
\hline Stout & 83 & 0.1 & 0.4 & 0.0 & 0.0 & 3.8 & 15.6 & 19.9 & 139.3 \\
\hline Beer & 67 & 0.1 & 0.4 & 0.0 & 0.0 & 0.2 & 0.8 & 9.5 & 66.5 \\
\hline $\begin{array}{l}\text { Sweet white } \\
\text { wine }\end{array}$ & 96 & 0.2 & 0.8 & 0.0 & 0.0 & 5.9 & 24.2 & 10.2 & 71.4 \\
\hline Cocktail & 141 & 0.2 & 0.8 & 0.9 & 8.4 & 9.1 & 37.3 & 13.7 & 95.9 \\
\hline
\end{tabular}

Table 1. Energy and caloric content of various alcoholic beverages per $100 \mathrm{~mL}$. Values were calculated with the software program EBIS pro and are based on the German food index.

Calories provided through the consumption of alcoholic beverages primarily stem from its content and metabolism of carbohydrates and ethanol. Indeed, hard spirits like whiskey, vodka and schnapps contain no sugar, whereas dry red and white wine contain 31 to 46 grams of sugar per liter. Sugar content of beer various between 2 and 38 grams per liter depending whether stout or "normal" beer is consumed. Sugar content may even be as high as 120 grams per liter in sweet white wine (on average $59 \mathrm{~g} / \mathrm{L}$ ) and up to 91 grams per liter in mixed cocktails (average value of several cocktails). A similarly strong variability in content is also found when ethanol contents of different alcoholic beverages are compared. For example, a liter of beer with the exception of stout on average contains 200 grams of ethanol per liter whereas wine contains 40 to 100 grams of ethanol per liter. Hard spirits may even contain up to 300 to even 500 grams of ethanol per liter. An average serving of wine $(125 \mathrm{~mL})$, beer $(330 \mathrm{~mL})$ or hard spirits $(40 \mathrm{~mL})$ contains 12 to 14 grams of ethanol. 


\subsection{Alcohol metabolism and energy yield}

Using bomb calorimetry it was shown that ethanol yields $7.1 \mathrm{kcal}(=29.3 \mathrm{~kJ})$ per gram when completely combusted (Lieber, 1991). However, as the digestibility of ethanol ranges from 98 to $100 \%$ and approximately $5 \%$ of ethanol is also lost through respiration, faeces and urine energy provide for metabolic purposes is only approximately $6.9 \mathrm{kcal}$ per gram ethanol (= $28.8 \mathrm{~kJ}$ per gram ethanol) (Lieber, 1991). It was further shown that even when ethanol is ingested at constant rates and high levels (e.g. up to 171 grams of ethanol per day) the loss of alcohol derived energy through the respiratory tract und urine only accounts to approximately $50 \mathrm{kcal}$ per day (Reinus et al. 1989). Indeed, a marked loss of ethanol through urine or respiration was only observed when the amounts of ethanol ingested exceed the liver's ethanol metabolizing capacity shown to be $105 \mathrm{mg} / \mathrm{kg}$ body weight per $\mathrm{h}$ (Reinus et al. 1989).

Taking the caloric content of alcoholic beverages into account and the fact that only little is lost through respiration, faeces, and urine, one would expect a positive association of alcohol intake and obesity. However, results of epidemiological studies are somewhat contradictory indicating no or only a weak association of alcohol consumption and body weight in men and even an inverse association in women (Müller et al. 1999). The results of these studies suggest that

- ethanol either bears a negative effect on energy yield implying that ethanol is inefficiently metabolised or

- the consumption of ethanol alters dietary intake, absorption and/ or metabolism of other nutrients subsequently leading to a negative or at least diminished energy yield.

In the very early studies of Atwater and Benedict (1902), using direct calorimetry it was shown that in healthy non-alcoholic volunteers ethanol (72 grams ethanol per day) was utilized as efficiently as fat or carbohydrates as a source of energy. Furthermore, it was shown that the ingestion of 31.5 gram of ethanol per $65 \mathrm{~kg}$ of body weight did not increase oxygen consumption or thermogenesis in normal volunteers (Barnes et al. 1965). However, contrary to these early finding, in the studies of Pirola and Lieber (1972), in which it was shown in normal volunteers that the progressive substitution of carbohydrates with ethanol in an otherwise balanced, normal diet results in a decrease in body weight. In line with these findings it was further shown that the addition of $90 \mathrm{~g}$ of ethanol to the daily diet increased the daily energy expenditure by 7\% (Suter et al. 1992) and that lipid oxidation may be inhibited by the ingestion of additional alcohol to 50\% of calories (Sonko et al. 1994). Furthermore, in a study in which the energy intake of middle-class patients with alcoholic liver disease ranging from non-cirrhotic to cirrhotic was compared to that of controls with the same body mass index it was shown that non-alcoholic energy intake did not differ from that of controls (Bergheim et al. 2003). In this study it was further shown that the average energy intake form alcoholic beverages (e.g. from beer, wine and hard spirits) accounting to $\sim 1008 \mathrm{kcal} /$ day $(=\sim 142 \mathrm{~g}$ Ethanol/ day) was added to the daily non-alcoholic energy intake without leading to the development of obesity. The results of this study are in line with other studies in which it was also shown that in middle-class alcohol consumers alcohol consumption is not associated with increased body weight compared with control subjects ingesting the same nonalcoholic energy intake, but lower total energy intake (Mezey, 1991; Rissanen et al. 1987). These data suggest that some of the energy ingested as alcohol is "lost" or "wasted"- that is, this energy is not available to the body for the production of energy 
resources that can be used to produce or maintain body mass. However, when interpreting these data, it has to be kept in mind that when assessing nutritional intake and herein especially that of alcohol underreporting may be a problem. For example, when applying the formula published by the WHO to calculate for underreporting to a study performed by Colditz et al. (1991) underreporting was found in $\sim 25 \%$ of women and $\sim 33 \%$ of men (Müller, 1999).

Several mechanisms have been proposed to be responsible for the apparent loss of alcoholderived energy. In the following, some of the main mechanisms proposed are summarized.

Three enzyme systems are known to be able to metabolize ethanol to acetaldehyde:

- the alcohol dehydrogenase (ADH), a cytolic enzyme existing as several isoenzymes, is the major enzyme metabolizing ethanol

- the microsomal ethanol oxidizing system (MEOS), a cytochrome P450-depending enzyme system, bound to the smooth endoplasmatic reticulum

- the catalase, localized in the peroxisomes, under normal conditions plays a neglectable role and therefore shall not be discussed here (for overview also see Zakhari (2006)).

The $\mathrm{ADH}$ is the major enzyme metabolizing ethanol. In order to facilitate the oxidation of ethanol $\mathrm{ADH}$ converts its cofactor nicotinamide adenine dinucleotide $\left(\mathrm{NAD}^{+}\right)$to $\mathrm{NADH}$. The reaction mediated by the $\mathrm{ADH}$ are summarized as

$$
\text { Ethanol }+\mathrm{NAD}^{+} \rightarrow \text { Acetaldehyde }+\mathrm{NADH}
$$

$\mathrm{NADH}$ is an energy rich molecule that can donate electrons to the electron transport chain in the mitochondria subsequently leading to the synthesis of adenosine triphosphate (ATP). However, as the ADH-mediated ethanol oxidation is located in the cytoplasm and NADH cannot pass the mitochondrial membrane the cellular redox potential is markedly altered when ethanol is metabolised (e.g. the $\mathrm{NADH} / \mathrm{NAD}^{+}$ratio) (van Haaren et al. 1999). As a consequence, ethanol derived NADH is mainly metabolized through the reduction of pyruvate to lactate and oxaloacetate to malate which in turn can then be used to utilize energy by the mitochondria (van Haaren et al. 1999). Acetaldehyde also produced in this reaction is rapidly metabolized, mainly by mitochondrial acetaldehyde dehydrogenase (ALDH) 2 to form acetate and $\mathrm{NADH}$, which than is oxidized by the electron transport chain (for overview also see (Zakhari and $\mathrm{Li}, 2007)$ ). The increase in mitochondrial NADH in hepatocytes resulting from the metabolism of acetaldehyde may result in a saturation of the NADH dehydrogenase and subsequently the impairment of the tricarboxylic acid (TCA) cycle as the acetyl coenzyme A (CoA) synthase 2, the mitochondrial enzyme involved in the oxidation of acetate is not found in the liver but is abundant in heart and skeletal muscles (Fujino et al. 2001). As a consequence, most of the acetate resulting from the breakdown of ethanol in the liver enters the circulation and is eventually metabolized to $\mathrm{CO}_{2}$ in the TCA in tissues that possess the enzymes to convert acetate to acetyl CoA (e.g. heart and skeletal muscle).

Furthermore, ethanol is also metabolised through the MEOS. The MEOS differs from the $\mathrm{ADH}$ in several aspects as it has a higher Michaelis constant $\left(\mathrm{K}_{\mathrm{m}}\right)$ (MEOS: $\mathrm{K}_{\mathrm{m}} 10 \mathrm{mM}$ vs. ADH: $K_{m}$ 1mM) (Haseba and Ohno, 2010; Lieber and DeCarli, 1970) and its activity increases when ethanol is consumed chronically (Lieber, 1997). The reaction mediated by the MEOS, which requires Nicotinamide adenine dinucleotide phosphate (NADPH) rather than $\mathrm{NAD}^{+}$and oxygen as a cofactor are summarized as 


$$
\text { Ethanol }+\mathrm{NADPH}+\mathrm{H}^{+}+1 / 2 \mathrm{O}_{2} \rightarrow \text { Acetaldehyde }+\mathrm{NADP}^{+}+2 \mathrm{H}_{2} \mathrm{O}
$$

This metabolic route of ethanol was proposed as one possible explanation of the energy "waste" associated with the intake of alcohol (Lieber, 1994; Lieber, 2003). Lieber (1991) postulated that when alcohol is consumed chronically alcohol is metabolized preferentially through the MEOS implying that the production of $\mathrm{NADP}^{+}$is increased whereas the formation of NADH through the $\mathrm{ADH}$ is decreased. This shift between the two enzyme systems would imply a loss in the net energy gain (e.g. through MEOS "only" $\sim 67 \%$ of the energy gain that is achieved if ethanol is metabolised through ADH). Lands and Zakhari (1991) calculated that if ethanol is readily metabolized through mitochondrial oxidation 1 Mol of ethanol can provide as much as $16 \mathrm{Mol}$ of ATP. In contrast the first steps of microsomal-mediated ethanol oxidation require $1 \mathrm{Mol}$ of NADPH equivalent to $3 \mathrm{Mol}$ ATP. Subsequently the energy yield through this pathway is markedly lower.

In addition, it was also postulated that the metabolism of acetate may also be associated with a loss of energy. Indeed, Müller et al. (1995 and 1998) showed that up to $80 \%$ of the acetate derived from ethanol metabolism in the human liver was found in the liver vein. It was further shown that in fasted subjects acetate blood levels raise with 90 min after ethanol ingestion up to $900-950 \mathrm{Mol} / \mathrm{L}$ after the ingestion of $47.5 \mathrm{~g}$ ethanol (Frayn et al. 1990). At the same time, acetate uptake by muscle tissue only accounted to $\sim 3 \%$ of the ingested ethanol. The enhanced energy use needed for the lipogenesis of acetate actually was calculated to account to $\sim 25 \%$ of the energy content of ethanol (Müller et al. 1999).

\subsection{Alcohol metabolism and its effect on general energy as well as fat, protein and carbohydrate metabolism}

The increased ratios of NADH to $\mathrm{NAD}^{+}$in both mitochondria and cytosol in hepatocytes affect the "direction" of several reversible reactions resulting in alterations of hepatic lipid, carbohydrate, and protein but also lactate and uric acid metabolism. The latter are not discussed in this chapter. Most of these changes have been shown to happen as a consequence of acute excessive alcohol intake (e.g. binge drinking) and seem to be at least in part to be attenuated when alcohol is consumed chronically; however, some alterations, like the accumulation of fat in the liver are also found when alcohol is consumed chronically. Furthermore, it has been shown that acute but also chronic intake of alcohol may not only affect micronutrient uptake in the small intestine but may also disturb the absorption of macronutrients; however, most of the data summarized in the following stem from animal experiments.

\subsubsection{Effect of alcohol intake on fat metabolism}

Besides an altered dietary pattern (e.g. higher intake of pork and subsequently polyunsaturated fatty acids) found to be associated with an increased intake of alcohol (French, 1992) results of early animal studies suggested that the concomitant ingestion of alcohol and plant derived oils is associated with a markedly reduced absorption of these fats (Bode, 1980); however, this effect of alcohol was probably due to a slowed gastric empting resulting from the combination of the oil with a relatively high dose of alcohol. In later human and animal studies it was found that absorption of lipids decreased by the ingestion of alcohol doses of $\geq 1 \mathrm{~g} / \mathrm{kg}$ body weight (Bode and Bode, 1992). It has further been 
suggested, that fat malabsorption found in patients with alcoholic hepatitis may be due to reduced bile and pancreas enzyme secretion (Soberon et al. 1987). Regarding the effects of alcohol metabolism on hepatic lipid metabolism it has been shown that the altered ratio of $\mathrm{NADH} / \mathrm{NAD}^{+}$results in an increase of the intermediate metabolite $\alpha$-glycerophosphate, which favours the accumulation of triglycerides in hepatocytes, but also inhibits $\beta$-oxidation of fatty acids in mitochondria (for overview also see Zakhari and Li (2007); Lieber (1984)).

\subsubsection{Effect of alcohol intake on protein metabolism}

In Europe the average intake of proteins has been shown to be normal in patients with chronic alcohol abuse or alcoholic liver disease in the earlier stage (e.g. steatohepatitis) (Bergheim et al. 2003). However, results of animal but also human studies suggest that absorption of amino acids in the small intestine is markedly impaired when alcohol is consumed concomitantly. Indeed, it has been shown in animal studies that in the presence of $2-4.5 \%$ of alcohol the uptake of L-alanin, L-glycine, L-leucine, L-proline, L-methionine, Lphenylalanin, and L-valin is in the small intestine impaired by more than $20 \%$ (Abidi et al. 1992). Especially the decreased uptake of methionine but also the inhibition of the methionine synthase in combination with the deficiency of folic acid and pyridoxine has been shown to be a critical factor in the development and progression of alcoholic liver disease. Recent data from animal studies suggest that the shift in the NADH/ NAD ${ }^{+}$ratio resulting from alcohol metabolism may also affect liver methionine metabolism (Watson et al. 2011). Indeed, it has been shown that the supplementation of methionine but also its metabolite S-adenosyl-L-methinone may improve alcoholic liver disease (for overview also see Beier and McClain (2010)).

\subsubsection{Effect of alcohol intake on hepatic glucose metabolism}

In animal experiments it was shown that alcohol at concentrations found in humans after moderate drinking (e.g. 1-5\% w/v) depresses glucose uptake in the brush border membrane in a dose- and time-dependent manner (Dinda and Beck, 1981). Furthermore, the increase in $\mathrm{NADH}$ resulting from the ADH-mediated oxidation of alcohol has been shown to prevent the conversion of pyruvate to glucose, which in turn impairs the rate limiting step of the gluconeogenesis, the pyruvate carboxylase reaction (Krebs et al. 1969) subsequently leading to hypoglycaemia. Fasting, sustained physical exercise and malnutrition may even increase the likelihood of hypoglycaemia.

\section{Alcohol and dietary pattern}

Alcohol consumption and potential alterations of dietary habits have been extensively studied in various cohort studies in various regions of the world (Thomson et al. 1988; Gruchow et al. 1985; Suter et al. 1997).

\subsection{Binge drinking and dietary pattern}

Kim et al. (2007) reported that both male and female binge drinkers have higher energy intake in comparison to non-binge drinkers. Among men, an inverse association between the frequency of binge drinking and the intake of polyunsaturated fatty acids (PUFA) including linoleic acid, a-linolenic acid and eicosapentaenoic acid was found; a similar 
association was not found in female binge drinkers (Kim et al. 2007). The lower intake of PUFA implies that binge drinking affects the choice of foods (e.g. intake of fish maybe lower) (Howe et al. 2006). Results of Toniolo et al. (1997) indicate that moderate drinkers (< $5 \mathrm{~g} / \mathrm{d}$ ) have reduced intake of milk and fresh fruits in comparison to abstainers (Toniolo et al. 1991). However, results of Thomson et al. (1988) found higher intake of fiber, cereal fiber and PUFA in moderate drinking group (0.1-9 g/day). Results of Colditz et al. (1991) found a strong correlation between alcohol intake and carbohydrates, and herein particularly the intake of sucrose. To further investigate this relation the study examined consumption of candy and chocolates. Results of this study are summarized in Table 2. In women the intake of only candy was negatively related with alcohol intake (Spearmann $\mathrm{r}=-0.07, \mathrm{p}<0.0001$ ).

\begin{tabular}{|c|c|c|c|}
\hline & \multicolumn{3}{|c|}{ Alcohol intake } \\
\hline & $0 \mathrm{~g} / \mathrm{d}$ & $9 g / d$ & $>50 \mathrm{~g} / \mathrm{d}$ \\
\hline \multirow{2}{*}{\multicolumn{4}{|c|}{$\begin{array}{l}\text { Women } \\
\text { Only candy }\end{array}$}} \\
\hline & & & \\
\hline Candy + chocolate & $3.12 \mathrm{~g} / \mathrm{d}$ & $3.12 \mathrm{~g} / \mathrm{d}$ & $3.40 \mathrm{~g} / \mathrm{d}$ \\
\hline Men & \multirow[b]{2}{*}{$1.98 \mathrm{~g} / \mathrm{d}$} & \multirow[b]{2}{*}{$1.70 \mathrm{~g} / \mathrm{d}$} & \multirow[b]{2}{*}{$0.85 \mathrm{~g} / \mathrm{d}$} \\
\hline Only candy & & & \\
\hline Candy + chocolate & $1.98 \mathrm{~g} / \mathrm{d}$ & $1.70 \mathrm{~g} / \mathrm{d}$ & $0.85 \mathrm{~g} / \mathrm{d}$ \\
\hline Chocolate & $3.69 \mathrm{~g} / \mathrm{d}$ & $3.69 \mathrm{~g} / \mathrm{d}$ & $2.27 \mathrm{~g} / \mathrm{d}$ \\
\hline
\end{tabular}

Table 2. Intake of alcohol vs. candy and chocolate in men and women (Adapted from Colditz et al. 1991).

Earlier studies have repeatedly documented that consumption of alcohol is associated with losses in tissue PUFA (Salen and Olsson, 1997; Lands et al. 1998).

\subsubsection{Chronic alcoholics, dietary pattern and nutritional intake}

In Germany and in most industrialized countries chronic alcohol abuse is not only one of the most important causes of nutritional disorders but also of changes in dietary habits (Aaseth et al. 1986; Addolorato, 1998; Suter et al. 1997). For instance, studies have reported that increased alcohol consumption is positively associated with an increased consumption of coffee, cheese, eggs, fish, meat whereas negative association was found with the intake of fruits and milk consumption (Kesse et al. 2001). Similar results were also reported by Toniolo et al. (1991) in regards to intake of fruit and dairy products. As mentioned above the results of Colditz et al. (1991) have reported that consumption of alcohol up to $50 \mathrm{~g} / \mathrm{d}$ was associated with lower intake of sugar in men. Results of Nanji et al. (1985) reported that pork and alcohol consumption were significantly correlated to cirrhosis mortality $(\mathrm{r}=0.98$, $\mathrm{p}<0.001)$. A study by Bergheim et al. (2003) performed on German male middle-class alcohol consumers found that in chronic alcohol consumption protein intake is within the recommended daily allowances. However, the intake of fat and carbohydrate was lower in alcohol consumers in comparison to controls. No significant differences were found in the intake of vitamin B1, B2, B6 and vitamin C as well as retinol in chronic alcohol consumers and controls. These results were in contrast with studies performed in the United States. 
Linangpunsakul et al. (2010) used the Third National Health and Nutritional Examination Survey (NHANES III) to examine an association between the nutritional intake and alcohol consumption in the United States. These data reveal that in both male and female participants the energy derived from carbohydrates, proteins and fat decreased with increased alcohol consumption. The subjects consumed less fat and protein with increased consumption of alcohol. This large population study concluded that alcohol has replaced nutrients particularly in terms of energy. Furthermore, the increased consumption of alcohol has an inverse relation with macronutrient intakes. Studies have also shown that in alcohol consumers hepatic zinc and vitamin A are found to be depleted due to poor dietary intake (Leo and Lieber, 1999). Taken together, the results gathered in the United States from the above studies differ from Europe, where alcohol was added to the diet but has not substituted nutrients from food sources.

\section{Alcohol and vitamins}

\subsection{Fat soluble vitamins}

Vitamin A: Vitamin A, which is vital for bone growth and normal eye function, is found to be deficient in patients with alcoholic cirrhosis (Lieber, 2003). Indeed, it has been found in human studies that patients with severe alcoholic liver disease have reduced levels of hepatic vitamin A (Ahmed et al. 1994). Interestingly, in these patients B-carotene levels in the blood were found to be normal, indicating that liver disease may modify the ability of liver to convert B-carotene to vitamin A (Ahmed et al. 1994). On the other hand, results of Manari et al. (2003) have indicated that chronic alcohol abusers without alcoholic liver disease have lower dietary intake of vitamin A than recommended by the reference nutrient intake. However, noteworthy results of Leo and Lieber (1982) showed that chronic alcohol administration in rats fed with vitamin A supplemented diet resulted in decrease of hepatic vitamin A levels. Thus, decreased levels of vitamin A in alcohol abuse may not be linked to reduced intake or malabsorption alone, suggesting that other mechanisms might be involved. Results of animal studies suggest that chronic ethanol ingestion has increased the peripheral vitamin A status and decreased hepatic vitamin A content (Leo et al. 1986; Leo and Lieber, 1988).

Vitamin D: Results of several human studies have reported that chronic alcohol abuse resulted in reduction of plasma 1,25 dihydroxyvitamin D3 levels, which is an active form of vitamin D3 (Lund et al. 1977; Laitinen and Valimaki, 1991; Laitinen et al. 1990). Similar reduction of plasma 1,25 dihydroxyvitamin D3 levels were also found in animal studies after chronic ethanol exposure (Turner et al. 1988). Reduction of circulating vitamin D levels in alcohol abusers may lead to reduced bone mass and lower calcium levels (Sampson, 1997; Keiver and Weinberg, 2003). Vitamin D is crucial in maintaining insulin levels and deficiencies may lead to altered glucose metabolism (Clark et al. 1981; Gedik and Akalin, 1986).

Vitamin E: Vitamin E is a well known anti-oxidant, whose metabolism is also altered in alcohol consumption (Drevon, 1991). Results of Bergheim et al. (2003) suggest that vitamin E consumption was markedly lower in patients with different stages of alcoholic liver disease. Furthermore, several animal and human studies suggest that consumption of alcohol reduces the hepatic stores of vitamin E (Bjorneboe et al. 1986, 1987, 1988a, 1988b). Indeed, rats fed with ethanol have increased hepatic a-tocopherol quinine levels, a product of a- 
tocopherol oxidation, suggesting that ethanol promotes vitamin E degradation (Kawase et al. 1989).

\subsection{Water soluble vitamins}

Thiamine: Thiamine or vitamin B1 is essential for proper neurological and cardiovascular functioning (Wood and Breen, 1979). Thiamine is available as free thiamine (T), thiamine diphosphate ester (TDP 80\%), thiamine triphosphate and thiamine monophosphate ester in the organism. Alcohol can inhibit the rate limiting mechanism of thiamine transport after its absorption from gastro-intestinal tract (Mancinelli and Ceccanti, 2009). In chronic alcohol abusers the concentrations of T and TDP were found to be reduced however, they were not related to liver injury (Mancinelli and Ceccanti, 2009). Furthermore, results of Manari et al. (2003) reported that $73 \%$ of the alcohol abusers have low thiamine intake in comparison to reference nutrient intake. Taken together, thiamine deficiency can be due to alcohol or malnutrition acting by itself or in combination.

Riboflavin: Riboflavin or vitamin B2 is an essential component of the cofactors flavin adenine dinucleotide and flavin mononucleotide. Riboflavin deficiency seems to be prevalent in alcoholics due to poor dietary intake (Manari et al. 2003). However, ethanol seems not to have an effect on riboflavin absorption (Pekkanen and Rusi, 1979).

Pyridoxine: Pyridoxine or vitamin B6 is an essential cofactor in amino acid metabolism. Studies have shown that $50 \%$ of alcohol abusers have lower circulating levels of pyridoxalphosphate (PLP), an indicator of vitamin B6 status; this deficiency might be attributed to poor dietary intake and demolition of the vitamin by phosphotases (Lumeng and Li, 1974; Lumeng, 1978; Fonda et al. 1989). Acetaldehyde, a product of ethanol oxidation in chronic alcohol abusers displaces protein bound PLP and exposes PLP to destruction of phosphotases (Lumeng and Li, 1974; Lumeng, 1978). Alteration in the amino acid metabolism due to PLP deficiency might be an aspect in the development of alcoholic liver disease. Indeed, animal studies have reported that chronic PLP deficient diet leads to the development of mild fatty liver (French and Castagna, 1967).

Folic acid: Folic acid or vitamin B9 plays an important role in facilitating many body processes. Folic acid deficiency is common in chronic alcohol abuse. For instance, a British study on alcoholics has reported that most of the patients had megaloblastic anaemia in association with lower liver folate levels and lower red blood cells (Wu et al. 1975). The causes of the deficiency are still unclear; however, numeral mechanisms have been proposed together with lower intake of folate, reduced intestinal absorption of polyglutamyl folates, alteration in hepatic and renal folate homeostasis and augmented folate catabolism (Halsted et al. 1973; Tamura and Halsted, 1983; Halsted et al. 1971; McMartin et al. 1989; Shaw et al. 1989).

Cobalamin: Vitamin B12 deficiency in chronic alcohol abusers is rare due to large hepatic deposits (Klipstein and Lindenbaum, 1965). Results of Kanazawa and Herbert (1985) reported higher levels of plasma vitamin B12 in chronic alcohol abusers than in controls. However, analysis of the hepatic tissue confirmed that vitamin B12 concentration was significantly lower in chronic alcoholics than in controls. Therefore, it might be concluded that chronic alcohol ingestion affects hepatic cobalamin homeostasis but probably also that of other organs (Cravo and Camilo, 2000). 


\section{Alcohol and minerals and trace elements}

Nutritional disturbances are assumed to remain among the most relevant medical problems in alcohol consumers (Aaseth et al. 1986; Addolorato, 1998; Suter et al. 1997) but it is still not clear whether chronic alcohol consumption per se results in malnutrition (Lieber, 2003; Leo et al. 1993; Leo and Lieber, 1999; Morgan and Levine, 1988). As reviewed by Lieber (2003), malnutrition and malsupplementation of certain micronutrients can be observed in alcohol abusers in the United States, whereas in another study dietary intake of German middleclass alcohol abusers with liver damage did not differ from that of control subjects consuming only very low amounts of ethanol (Bergheim et al. 2003). However, malsupplementation or an excessive intake of special micronutrients may contribute to the development of hepatic damage in alcoholic liver disease in single cases.

\subsection{Iron}

In contrast to other micronutrients iron is known to promote liver damage. Oxidative stress plays a key role in the pathogenesis of alcoholic liver diseases. By catalyzing the conversion of superoxide and hydrogen peroxide to hydroxyl radicals, iron can contribute to induce oxidative stress and, thus, induce liver cirrhosis in experimental settings in rats treated with ethanol (Tsukamoto et al. 1995). In other studies with rodents, iron also increased the hepatotoxicity caused by alcohol (Stal and Hultcrantz, 1993). Alcoholic liver diseases are often associated with an iron overload (Kohgo et al. 2008). Even mild to moderate alcohol consumption has recently been shown to increase the prevalence of iron overload (Ioannou et al. 2004). Iron has been shown to accumulate in Kupffer cells as well as in hepatocytes (Farinati et al. 1995; Ioannou et al. 2004). However, the mechanisms involved in the accumulation of iron in the liver when alcohol is ingested chronically are still poorly understood. Two possible mechanisms that are discussed to lead to an accumulation of iron in alcohol-inuced liver diseases are 1. an increased uptake of iron into hepatocytes, 2. an increased intestinal absorption of iron (Kohgo et al. 2008). In a study in Japanese patients with alcoholic liver disease it has been shown that the expression of transferrin receptor 1 was increased in hepatocytes (Suzuki et al. 2002) indicating that ethanol may increase iron uptake in hepatocytes. Another important factor that may be involved in iron overload found in patients with alcoholic liver disease is the systemic iron hormone hepcidin. Hepcidin plays an important role in duodenal iron absorption. In recent years it has been shown that hepcidin expression is downregulated in alcoholic liver disease (for overview see (Kohgo et al. 2008)).

\subsection{Zinc}

Zinc is an essential trace element and the daily recommended intake for adults ranges from $7 \mathrm{mg}$ to $11 \mathrm{mg}$. Zinc plays an essential role not only in catalytic reactions but also in the maintenance of the structural integrity of proteins by forming a "zinc finger-like" structure created by chelation centers, including cysteine and histidine residues (Klug and Schwabe, 1995) and in the regulation of gene expression. For example, metallothionein expression is regulated by a mechanism that involves the binding of zinc to the metal regulatory transcription factor 1, which in turn activates gene transcription (Cousins, 1994; Dalton et al. 1997). Zinc is necessary for the function of nearly 100 specific enzymes (e.g. alcohol dehydrogenase, retinol dehydrogenase) and is essential for macronutrient metabolism (e.g. 
carbohydrate and protein metabolism), wound healing, the immune system, glucose control, growth, digestion, and fertility (King and Cousins, 2005; Prasad, 1995; Lipscomb and Strater, 1996). In alcoholic abusers, evidence of zinc deficiency has been reported repeatedly (Aaseth et al. 1986; Bjorneboe et al. 1988). Results of a study in German middle-class alcohol consumers indicated that zinc concentrations in plasma were significantly decreased in alcohol consumers with different stages of alcoholic liver diseases (fatty liver, hepatitis, cirrhosis), whereas urinary zinc loss was increased in this patients (Bergheim et al. 2003). This is in line with the findings of previous studies, which reported decreased intestinal absorption of zinc (Valberg et al. 1985; Dinsmore et al. 1985) and increased zinc excretion in urine (Sullivan, 1962) being the most important reasons for zinc deficiency caused by alcohol consumption. Indeed, zinc deficiency is one of the most commonly observed nutritional manifestations of alcoholic liver disease (McClain et al. 1991). It has been discussed by Kang and Zhou (2005) that a supplementation of zinc may have a high potential to be developed as an effective agent in the prevention and treatment of alcoholic liver disease.

\subsection{Copper}

Copper plays an essential role as component of a number of metalloenzymes acting as oxidases (e.g cytochrome c oxidase). The daily recommended intake for adults ranges from $0.9 \mathrm{mg}$ to $1.5 \mathrm{mg}$. In humans, an isolated copper deficiency rarely occurs and is normally due to an insufficient intake. However, the consumption of alcohol has been shown to be associated with a significant reduction of the levels of copper in serum (Schuhmacher et al. 1994). Results of a study in patients with alcoholic cirrhosis indicate that liver copper contents and urinary copper excretion were higher in cirrhotic patients and were related with the severity of chronic alcoholic liver disease (Rodriguez-Moreno et al., 1997). Besides zinc, copper is an essential cofactor of the copper/zinc superoxide dismutase, which is an enzyme that catalyzes the dismutation of superoxide into oxygen and hydrogen peroxide. In the liver, one of the most important antioxidants is the copper/zinc superoxide dismutase (Suter, 2005). In biopsies from patients with alcoholic liver disease it has been shown that the amount of copper/zinc superoxide dismutase reactivity was significantly lower than in control biopsies (Zhao et al., 1996).

\subsection{Magnesium}

As a cofactor for more than 300 enzyme systems (Wacker and Parisi, 1968) magnesium plays an essential role in anaerobic and aerobic energy generation and in glycolysis, being part of the Magnesium-ATP complex or acting as an enzyme activator (Garfinkel and Garfinkel, 1985). The daily recommended intake for adults is 300-400mg. Magnesium deficiency leads to many specific and unspecific symptoms such as anxiety, insomnia, nervousness, high blood pressure, and muscle spasms. Alcohol abusers are at high risk for magnesium deficiency because alcohol dose-dependently increases urinary excretion of magnesium (Laitinen et al. 1992). Even in cases of moderate alcohol consumption an increased excretion of magnesium in urine can be observed (Rylander et al. 2001). In dependence on the severity of alcohol abuse, 30 to $60 \%$ of alcoholics and nearly $90 \%$ of patients experiencing alcohol withdrawal have low magnesium levels in serum/plasma (Flink, 1986). The increased loss of magnesium may be potentiated by an insufficient intake or by an intestinal loss (e.g. through diarrhoea and vomiting). 


\subsection{Selenium}

Selenium plays an important role as cofactor in several enzyme systems, such as the glutathione peroxidase, which acts as a cellular protector against free radical oxidative damage (Foster and Sumar, 1997). Low levels of selenium in plasma, serum or blood have not only been reported in patients with alcohol-induced cirrhosis but also in other liver diseases (for overview see McClain et al. (1991)). Results of a study in German middle-class alcohol consumers indicated that selenium concentrations in plasma and in erythrocytes were significantly decreased in alcohol consumers with different stages of alcoholic liver diseases compared to healthy controls, although the dietary intake of selenium was not decreased in these patients with alcoholic liver disease (Bergheim et al. 2003). In contrast, in other studies depressed serum selenium concentrations correlated closely with poor nutritional status (Tanner et al. 1986) and with the severity of alcohol-induced liver damage (Dworkin et al. 1985). In patients with alcohol-induced cirrhosis an additional decreased content of selenium in the liver was observed (Dworkin et al. 1988).

\section{Clinical manifestation, diagnosis and therapy of malnutrition}

As discussed in the previous sections of this chapter, alcohol consumption and herein particularly chronic intake of alcohol but also alcohol metabolism is associated with numerous alterations such as changes in dietary pattern (e.g. elevated intake of pork), impaired intestinal absorption of micro- but also macronutrients but also metabolism in the liver. As a consequence malnutrition is frequently found in patients with alcoholic liver disease. Indeed, as reviewed by Stickel et al. (2003), malnutrition can be both, a primary event resulting from a poor diet and decreased caloric intake but also a secondary process resulting from malabsorption and maldigestion. The question if the progression of alcoholic liver disease can be improved by nutritional support to these patients has been addressed in several clinical trails using oral, enteral, or parenteral routs to deliver nutritional formulas (for overview also see Halsted (2004; DiCecco and Francisco-Ziller (2006)). However, many of the studies were inconclusive as in some studies control groups were inadequate or control formulas were unbalanced, duration of studies was too short or nutritional needs were not adequately assessed (Halsted, 2004). In the following, methods for the assessment of nutritional status and recommendations for nutritional support of patients with alcoholic liver disease are briefly summarized (for overview also see Halsted (2004; DiCecco and Francisco-Ziller (2006; Plauth et al. (2006)).

\subsection{Assessment of nutritional status}

Assessing the nutritional status of a patient with alcoholic liver disease may be challenging as many of the traditional tools may be affected by the disease (e.g. body weight changes may stem from fluctuation in oedema or ascites). Indeed, diminished serum levels of hepatic protein such as albumin and transferrin may rather be indication of an altered protein biosynthesis in the liver than a protein caloric malnutrition (Fuhrman et al. 2004). In patients without fluid overload, midarm muscle area and creatinine excretion in urine have been shown to be the most reliable measures of nutritional status, whereas in those patients with ascites and oedema creatinine height index is more reliable (Nielsen et al. 1993). Furthermore, serum status of vitamins such as A, D, E, and folate as well as minerals like zinc and iron as well as skin turgor, poor oral health and temporal muscle wasting or night 
blindness should also be assessed and may also help to identify losses of muscle mass and micronutrient deficiencies (Figueiredo et al. 2000). The subjective global assessment method, which combines subjective and objective measures has been found to accurately reflect the nutritional status of patients with end-stage liver disease (Hirsch et al. 1991, Hasse et al. 1993). Taken together, a detailed diet history, anthropometric measurements (e.g. triceps skinfold, arm circumference, body mass index), and measurements of handgrip strength but also measurements of vitamin and mineral status in serum are recommended when nutritionally assessing patients with alcoholic liver disease (DiCecco and Francisco-Ziller, 2006).

\subsection{Oral nutritional supplementation}

One of the first-line therapies to prevent and treat malnutrition in patients with alcoholic liver disease is through oral feeding including supplements. Herein, avoiding a fasting state, minimizing dietary restrictions, and offering small, frequent feedings is critical to meet the caloric and protein requirements (DiCecco and Francisco-Ziller, 2006). The benefit of oral nutritional supplementation has been assessed in many studies; however, due to poor study design or to small patients numbers included a final conclusion regarding the efficacy of this approach cannot yet be drawn. As reviewed by Stickel et al. (2003) and Halsted (2004) and stated in the guidelines from the European Society for Clinical Nutrition and Metabolism (ESPEN) on enteral nutrition for patients with liver disease (Plauth et al. 2006) oral nutritional supplements may improve nutritional status and complications of alcoholic liver disease and are recommend, although the true effect on survival is still unknown.

\subsection{Enteral nutritional supplementation}

Enteral tube feeding is second option to treat malnutrition in patients with alcoholic liver disease and is especially considered a save and efficient way to improve the nutritional status in those patients unable or willing to consume adequate oral nutrition. Indeed, despite the sometimes poor patient acceptance of the tube feeding it has been shown in several studies, that tube feeding may improve digestion but also has a short-term positive effect on liver function and may improve long-term survival (for overview also see Halsted, (2004; Plauth et al. (2006)).

\subsection{Parenteral nutritional supplementation}

The advantage of parenteral nutrition is the delivery of a precisely defined amount of protein, total calories, micronutrients, fluid, and electrolytes; however, clinical trails performed to evaluate the effect of parenteral nutrition in patients with alcoholic liver disease are difficult to interpret as study design was mostly inadequate (e.g. intake of controls was not adjusted, length of study, follow-up). The ESPEN guidelines advise that parental formula should provide adequate calories and protein with careful monitoring of glucose and electrolytes (Plauth et al. 2006).

\section{Conclusion}

Results of several studies suggest that quantity and frequency of alcohol consumption are important in the pathogenesis of alcoholic liver disease. Malnutrition is frequently present 
in patients with alcoholic liver disease and may result from an altered dietary pattern, disturbed intestinal absorption and nutrient utilization in the liver due to the concomitant alcohol metabolism and/ or alcohol-induced impairments of liver function. Nutritional support including provision of adequate calories and protein but also micronutrients avoiding extended fasting periods and restricted diets may help to improve health status of patients with alcoholic liver disease; however, more clinical trails are needed to clarify the long-term effects of nutritional treatment on liver status and survival in patients with alcoholic liver disease.

\section{References}

Aaseth, J., Smith-Kielland, A. \& Thomassen, Y. (1986). Selenium, alcohol and liver diseases. Ann.Clin.Res. 18(1):43-47.

Abidi, S.A. et al. (1992). In Lieber C.S.. ed. Medical and Nutritional Complications of Alcoholism: Mechanisms and Management. New York: Plenum Press, pp 127-155

Addolorato, G. (1998). Chronic alcohol abuse and nutritional status: recent acquisitions. Eur.Rev.Med.Pharmacol.Sci. 2(5-6):165-167.

Ahmed, S., Leo, M.A. \& Lieber, C.S. (1994). Interactions between alcohol and beta-carotene in patients with alcoholic liver disease. Am.J Clin.Nutr 60(3):430-436.

Atwater, W.O., Benedict, F.G. (1902). An experimental inquiry regarding the nutritive value of alcohol. Mem Natl Acad Sci. 8:235-295

Barnes, E.W., Cooke, N.J., King, A.J. \& Passmore, R. (1965). Observations on the metabolism of alcohol in man. Br.J.Nutr 19(4):485-489.

Beier, J.I. \& McClain, C.J. (2010). Mechanisms and cell signaling in alcoholic liver disease. Biol.Chem. 391(11):1249-1264.

Bellentani, S., Saccoccio, G., Costa, G., Tiribelli, C., Manenti, F., Sodde, M., Saveria, C.L., Sasso, F., Pozzato, G., Cristianini, G. \& Brandi, G. (1997). Drinking habits as cofactors of risk for alcohol induced liver damage. The Dionysos Study Group. Gut 41(6):845-850.

Bergheim, I., Parlesak, A., Dierks, C., Bode, J.C. \& Bode, C. (2003). Nutritional deficiencies in German middle-class male alcohol consumers: relation to dietary intake and severity of liver disease. Eur.J.Clin Nutr 57(3):431-438.

Bjorneboe, A., Bjorneboe, G.E., Bodd, E., Hagen, B.F., Kveseth, N. \& Drevon, C.A. (1986). Transport and distribution of alpha-tocopherol in lymph, serum and liver cells in rats. Biochim.Biophys.Acta 889(3):310-315.

Bjorneboe, G.E., Bjorneboe, A., Hagen, B.F., Morland, J. \& Drevon, C.A. (1987). Reduced hepatic alpha-tocopherol content after long-term administration of ethanol to rats. Biochim.Biophys.Acta 918(3):236-241.

Bjorneboe, G.E., Johnsen, J., Bjorneboe, A., Bache-Wiig, J.E., Morland, J. \& Drevon, C.A. (1988a). Diminished serum concentration of vitamin E in alcoholics. Ann.Nutr Metab 32(2):56-61.

Bjorneboe, G.E., Johnsen, J., Bjorneboe, A., Marklund, S.L., Skylv, N., Hoiseth, A., BacheWiig, J.E., Morland, J. \& Drevon, C.A. (1988b). Some aspects of antioxidant status in blood from alcoholics. Alcohol Clin.Exp.Res. 12(6):806-810.

Bode, J.C. (1980). Alcohol and the gastrointestinal tract. Adv Intern Med Ped. 45:1-75.

Bode, J.C., Bode, C. (1992). Alcohol malnutrition and the gastrointestinal tract. In: Watson, R.R., Watzl, B. (eds) Nutrition and alcohol, CRC Press Boca Raton, pp 403-428. 
Burger, M., Bronstrup, A. \& Pietrzik, K. (2004). Derivation of tolerable upper alcohol intake levels in Germany: a systematic review of risks and benefits of moderate alcohol consumption. Prev.Med. 39(1):111-127.

Clark, S.A., Stumpf, W.E. \& Sar, M. (1981). Effect of 1, 25 dihydroxyvitamin D3 on insulin secretion. Diabetes 30(5):382-386.

Colditz, G.A., Giovannucci, E., Rimm, E.B., Stampfer, M.J., Rosner, B., Speizer, F.E., Gordis, E. \& Willett, W.C. (1991). Alcohol intake in relation to diet and obesity in women and men. Am.J.Clin Nutr 54(1):49-55.

Cousins, R.J. (1994). Metal elements and gene expression. Annu.Rev.Nutr 14:449-469.

Cravo, M.L. \& Camilo, M.E. (2000). Hyperhomocysteinemia in chronic alcoholism: relations to folic acid and vitamins B(6) and B(12) status. Nutrition 16(4):296-302.

Dalton, T.P., Bittel, D. \& Andrews, G.K. (1997). Reversible activation of mouse metal response element-binding transcription factor 1 DNA binding involves zinc interaction with the zinc finger domain. Mol.Cell Biol. 17(5):2781-2789.

Dantzer, C., Wardle, J., Fuller, R., Pampalone, S.Z. \& Steptoe, A. (2006). International study of heavy drinking: attitudes and sociodemographic factors in university students. J.Am.Coll.Health 55(2):83-89.

Day, C.P. (1997). Alcoholic liver disease: dose and threshold--new thoughts on an old topic. Gut 41(6):857-858.

Deutsche Hauptstelle für Suchtfragen (DHS). Available on: http://www.dhs.de/datenfakten/alkohol.html.

DiCecco, S.R. \& Francisco-Ziller, N. (2006). Nutrition in alcoholic liver disease. Nutr Clin Pract. 21(3):245-254.

Dinda, P.K. \& Beck, I.T. (1981). Ethanol-induced inhibition of glucose transport across the isolated brush-border membrane of hamster jejunum. Dig.Dis.Sci. 26(1):23-32.

Dinsmore, W., Callender, M.E., McMaster, D., Todd, S.J. \& Love, A.H. (1985). Zinc absorption in alcoholics using zinc-65. Digestion 32(4):238-242.

Drevon, C.A. (1991). Absorption, transport and metabolism of vitamin E. Free Radic.Res.Commun. 14(4):229-246.

Dworkin, B., Rosenthal, W.S., Jankowski, R.H., Gordon, G.G. \& Haldea, D. (1985). Low blood selenium levels in alcoholics with and without advanced liver disease. Correlations with clinical and nutritional status. Dig.Dis.Sci. 30(9):838-844.

Dworkin, B.M., Rosenthal, W.S., Stahl, R.E. \& Panesar, N.K. (1988). Decreased hepatic selenium content in alcoholic cirrhosis. Dig.Dis.Sci. 33(10):1213-1217.

Farinati, F., Cardin, R., de, M.N., Della, L.G., Marafin, C., Lecis, E., Burra, P., Floreani, A., Cecchetto, A. \& Naccarato, R. (1995). Iron storage, lipid peroxidation and glutathione turnover in chronic anti-HCV positive hepatitis. J.Hepatol. 22(4):449456.

Figueiredo, F.A., Dickson, E.R., Pasha, T.M., Porayko, M.K., Therneau, T.M., Malinchoc, M., DiCecco, S.R., Francisco-Ziller, N.M., Kasparova, P. \& Charlton, M.R. (2000). Utility of standard nutritional parameters in detecting body cell mass depletion in patients with end-stage liver disease. Liver Transpl. 6(5):575-581.

Flink, E.B. (1986). Magnesium deficiency in alcoholism. Alcohol Clin Exp.Res. 10(6):590-594.

Fonda, M.L., Brown, S.G. \& Pendleton, M.W. (1989). Concentration of vitamin B6 and activities of enzymes of B6 metabolism in the blood of alcoholic and nonalcoholic men. Alcohol Clin.Exp.Res. 13(6):804-809. 
Foster, L.H. \& Sumar, S. (1997). Selenium in health and disease: a review. Crit Rev.Food Sci.Nutr 37(3):211-228.

Frayn, K.N., Coppack, S.W., Walsh, P.E., Butterworth, H.C., Humphreys, S.M. \& Pedrosa, H.C. (1990). Metabolic responses of forearm and adipose tissues to acute ethanol ingestion. Metabolism 39(9):958-966.

French, S.W. (1992). Nutritional factors in the pathogenesis of alcoholic liver disease. In: Watson, R.R., Watzl, B. (eds) Nutrition and alcohol, CRC Press Boca Raton, pp 403428.

French, S.W. \& Castagna, J. (1967). Some effects of chronic ethanol feeding on vitamin B 6 deficiency in the rat. Lab Invest 16(4):526-531.

Fuhrman, M.P., Charney, P., Mueller, C.M. (2004). Hepatic proteins and nutrition assessment. J Am Diet Assoc. 104(8):1258-64.

Fujino, T., Kondo, J., Ishikawa, M., Morikawa, K. \& Yamamoto, T.T. (2001). Acetyl-CoA synthetase 2, a mitochondrial matrix enzyme involved in the oxidation of acetate. J.Biol.Chem. 276(14):11420-11426.

Garfinkel, L. \& Garfinkel, D. (1985). Magnesium regulation of the glycolytic pathway and the enzymes involved. Magnesium 4(2-3):60-72.

Gedik, O. \& Akalin, S. (1986). Effects of vitamin D deficiency and repletion on insulin and glucagon secretion in man. Diabetologia 29(3):142-145.

Gruchow, H.W., Sobocinski, K.A., Barboriak, J.J. \& Scheller, J.G. (1985). Alcohol consumption, nutrient intake and relative body weight among US adults. Am.J Clin.Nutr 42(2):289-295.

Halsted, C.H. (2004). Nutrition and alcoholic liver disease. Semin.Liver Dis. 24(3):289-304.

Halsted, C.H., Robles, E.A. \& Mezey, E. (1971). Decreased jejunal uptake of labeled folic acid ( 3 H-PGA) in alcoholic patients: roles of alcohol and nutrition. N.Engl.J Med. 285(13):701-706.

Halsted, C.H., Robles, E.A. \& Mezey, E. (1973). Intestinal malabsorption in folate-deficient alcoholics. Gastroenterology 64(4):526-532.

Haseba, T. \& Ohno, Y. (2010). A new view of alcohol metabolism and alcoholism--role of the high-Km Class III alcohol dehydrogenase (ADH3). Int.J.Environ.Res.Public Health 7(3):1076-1092.

Hasse, J., Strong, S., Gorman, M.A. \& Liepa, G. (1993). Subjective global assessment: alternative nutrition-assessment technique for liver-transplant candidates. Nutrition 9(4):339-343.

Hirsch, S., de Obaldia, N., Petermann, M., Rojo, P., Barrientos, C., Iturriaga, H., Bunout, D. (1991). Subjective global assessment of nutritional status: further validation. Nutrition. 7(1):35-7.

Howe, P., Meyer, B., Record, S. \& Baghurst, K. (2006). Dietary intake of long-chain omega-3 polyunsaturated fatty acids: contribution of meat sources. Nutrition 22(1):47-53.

Institute of Alcohol Studies. (2010). Binge Drinking - Nature, prevalence and causes. London, UK; Available from: www.ias.org.uk/resources/factsheets/binge_drinking.pdf

Ioannou, G.N., Dominitz, J.A., Weiss, N.S., Heagerty, P.J. \& Kowdley, K.V. (2004). The effect of alcohol consumption on the prevalence of iron overload, iron deficiency, and iron deficiency anemia. Gastroenterology 126(5):1293-1301.

Kamper-Jorgensen, M., Gronbaek, M., Tolstrup, J. \& Becker, U. (2004). Alcohol and cirrhosis: dose--response or threshold effect? J.Hepatol. 41(1):25-30. 
Kanazawa, S. \& Herbert, V. (1985). Total corrinoid, cobalamin (vitamin B12), and cobalamin analogue levels may be normal in serum despite cobalamin in liver depletion in patients with alcoholism. Lab Invest 53(1):108-110.

Kang, Y.J. \& Zhou, Z. (2005). Zinc prevention and treatment of alcoholic liver disease. Mol.Aspects Med. 26(4-5):391-404.

Kanny, D., Liu, Y. \& Brewer, R.D. (2011). Binge drinking - United States, 2009. MMWR Surveill Summ. 60 Suppl:101-104.

Kawase, T., Kato, S. \& Lieber, C.S. (1989). Lipid peroxidation and antioxidant defense systems in rat liver after chronic ethanol feeding. Hepatology 10(5):815-821.

Keiver, K. \& Weinberg, J. (2003). Effect of duration of alcohol consumption on calcium and bone metabolism during pregnancy in the rat. Alcohol Clin.Exp.Res. 27(9):1507-1519.

Kesse, E., Clavel-Chapelon, F., Slimani, N. \& van, L.M. (2001). Do eating habits differ according to alcohol consumption? Results of a study of the French cohort of the European Prospective Investigation into Cancer and Nutrition (E3N-EPIC). Am.J Clin.Nutr 74(3):322-327.

Kim, S.Y., Breslow, R.A., Ahn, J. \& Salem, N., Jr. (2007). Alcohol consumption and fatty acid intakes in the 2001-2002 National Health and Nutrition Examination Survey. Alcohol Clin.Exp.Res. 31(8):1407-1414.

King J, Cousins RJ. (2005). In: Shils ME, Shike M, Ross AC, CaballeroB, Cousins RJ, editors. Modern nutrition in health and disease, $10^{\text {th }}$ ed. Baltimore, MD: Lippincott Williams \& Wilkins: 271-285.

Klipstein, F.A. \& Lindenbaum, J. (1965). FOLATE DEFICIENCY IN CHRONIC LIVER DISEASE. Blood 25:443-456.

Klug, A. \& Schwabe, J.W. (1995). Protein motifs 5. Zinc fingers. FASEB J. 9(8):597-604.

Kohgo, Y., Ohtake, T., Ikuta, K., Suzuki, Y., Torimoto, Y. \& Kato, J. (2008). Dysregulation of systemic iron metabolism in alcoholic liver diseases. J.Gastroenterol.Hepatol. 23 Suppl 1:S78-S81.

Krebs, H.A., Freedland, R.A., Hems, R. \& Stubbs, M. (1969). Inhibition of hepatic gluconeogenesis by ethanol. Biochem.J. 112(1):117-124.

Laitinen, K., Tahtela, R. \& Valimaki, M. (1992). The dose-dependency of alcohol-induced hypoparathyroidism, hypercalciuria, and hypermagnesuria. Bone Miner. 19(1):7583.

Laitinen, K. \& Valimaki, M. (1991). Alcohol and bone. Calcif.Tissue Int. 49 Suppl:S70-S73.

Laitinen, K., Valimaki, M., Lamberg-Allardt, C., Kivisaari, L., Lalla, M., Karkkainen, M. \& Ylikahri, R. (1990). Deranged vitamin D metabolism but normal bone mineral density in Finnish noncirrhotic male alcoholics. Alcohol Clin.Exp.Res. 14(4):551-556.

Lands WEM, Pawlosky RJ \& Salem N Jr (1998). Alcoholism, antioxidant status and essential fatty acids. In Antioxidants in Nutrition and Health, pp. 299-344. (Anonymous). Boca Raton, FL: CRC Press].

Lands, W.E. \& Zakhari, S. (1991). The case of the missing calories. Am.J.Clin Nutr 54(1):47-48.

Lelbach, W.K. (1975). Cirrhosis in the alcoholic and its relation to the volume of alcohol abuse. Ann.N.Y.Acad.Sci. 252:85-105.

Leo M A \& Lieber C S (1982). Hepatic vitamin A depletion in alcoholic liver injury. N.Engl.J Med. 307:597-601. 
Leo, M.A., Kim, C. \& Lieber, C.S. (1986). Increased vitamin A in esophagus and other extrahepatic tissues after chronic ethanol consumption in the rat. Alcohol Clin.Exp.Res. 10(5):487-492.

Leo, M.A. \& Lieber, C.S. (1988). Hypervitaminosis A: a liver lover's lament. Hepatology 8(2):412-417.

Leo, M.A. \& Lieber, C.S. (1999). Alcohol, vitamin A, and beta-carotene: adverse interactions, including hepatotoxicity and carcinogenicity. Am.J.Clin Nutr 69(6):1071-1085.

Leo, M.A., Rosman, A.S. \& Lieber, C.S. (1993). Differential depletion of carotenoids and tocopherol in liver disease. Hepatology 17(6):977-986.

Liangpunsakul, S. (2010). Relationship between alcohol intake and dietary pattern: findings from NHANES III. World J Gastroenterol. 16(32):4055-4060.

Lieber, C.S. (1984). Alcohol and the liver: 1984 update. Hepatology 4(6):1243-1260.

Lieber, C.S. (1991). Perspectives: do alcohol calories count? Am.J.Clin Nutr 54(6):976-982.

Lieber, C.S. (1994). Alcohol and the liver: 1994 update. Gastroenterology 106(4):1085-1105.

Lieber, C.S. (1997). Ethanol metabolism, cirrhosis and alcoholism. Clin Chim.Acta 257(1):5984.

Lieber, C.S. (2003). Relationships between nutrition, alcohol use, and liver disease. Alcohol Res.Health 27(3):220-231.

Lieber, C.S. \& DeCarli, L.M. (1970). Hepatic microsomal ethanol-oxidizing system. In vitro characteristics and adaptive properties in vivo. J.Biol.Chem. 245(10):2505-2512.

Lipscomb, W.N. \& Strater, N. (1996). Recent Advances in Zinc Enzymology. Chem.Rev. 96(7):2375-2434.

Lumeng, L. (1978). The role of acetaldehyde in mediating the deleterious effect of ethanol on pyridoxal 5'-phosphate metabolism. J Clin.Invest 62(2):286-293.

Lumeng, L. \& Li, T.K. (1974). Vitamin B6 metabolism in chronic alcohol abuse. Pyridoxal phosphate levels in plasma and the effects of acetaldehyde on pyridoxal phosphate synthesis and degradation in human erythrocytes. J Clin.Invest 53(3):693-704.

Lund, B., Sorensen, O.H., Hilden, M. \& Lund, B. (1977). The hepatic conversion of vitamin D in alcoholics with varying degrees of liver affection. Acta Med.Scand. 202(3):221-224.

Manari, A.P., Preedy, V.R. \& Peters, T.J. (2003). Nutritional intake of hazardous drinkers and dependent alcoholics in the UK. Addict.Biol. 8(2):201-210.

Mancinelli, R. \& Ceccanti, M. (2009). Biomarkers in alcohol misuse: their role in the prevention and detection of thiamine deficiency. Alcohol Alcohol 44(2):177-182.

McClain, C.J., Marsano, L., Burk, R.F. \& Bacon, B. (1991). Trace metals in liver disease. Semin.Liver Dis. 11(4):321-339.

McMartin, K.E., Collins, T.D., Eisenga, B.H., Fortney, T., Bates, W.R. \& Bairnsfather, L. (1989). Effects of chronic ethanol and diet treatment on urinary folate excretion and development of folate deficiency in the rat. J Nutr 119(10):1490-1497.

Mezey, E. (1991). Interaction between alcohol and nutrition in the pathogenesis of alcoholic liver disease. Semin.Liver Dis. 11(4):340-348.

Morgan, M.Y. \& Levine, J.A. (1988). Alcohol and nutrition. Proc.Nutr Soc. 47(2):85-98.

Müller, M.J. (1995). Hepatic fuel selection. Proc Nutr Soc. 54:139.

Müller, M.J. (1998). Hepatic energy and substrate metabolism: A possible metabolic basis for early nutritional support in cirrhotic patients. Nutrition. 14:30-38. 
Müller, M.J. (1999). Alkohol: Kalorie oder leere Kalorie?. In: Alkohol und Alkoholfolgekrankheiten Grundlagen - Diagnostik - Therapie, Singer, M.V., Teyssen, S., pp. 85-94, Springer Berlin Heidelberg, ISBN 3-540-65094-6.

Nanji, A.A. \& French, S.W. (1985). Relationship between pork consumption and cirrhosis. Lancet 1(8430):681-683.

National Institute on Alcohol Abuse and Alcoholism. (2007). What colleges need to know now: An update on college drinking research. (NIH Pub. No. 07-5010). Washington, DC: National

Nielsen, K., Kondrup, J., Martinsen, L., Stilling, B. \& Wikman, B. (1993). Nutritional assessment and adequacy of dietary intake in hospitalized patients with alcoholic liver cirrhosis. Br.J.Nutr 69(3):665-679.

Pekkanen, L. \& Rusi, M. (1979). The effects of dietary niacin and riboflavin on voluntary intake and metabolism of ethanol in rats. Pharmacol.Biochem Behav. 11(5):575-579.

Pirola, R.C. \& Lieber, C.S. (1972). The energy cost of the metabolism of drugs, including ethanol. Pharmacology 7(3):185-196.

Plauth, M., Cabre, E., Riggio, O., ssis-Camilo, M., Pirlich, M., Kondrup, J., Ferenci, P., Holm, E., Vom, D.S., Muller, M.J. \& Nolte, W. (2006). ESPEN Guidelines on Enteral Nutrition: Liver disease. Clin Nutr 25(2):285-294.

Prasad, A.S. (1995). Zinc: an overview. Nutrition 11(1 Suppl):93-99.

Reinus, J.F., Heymsfield, S.B., Wiskind, R., Casper, K. \& Galambos, J.T. (1989). Ethanol: relative fuel value and metabolic effects in vivo. Metabolism 38(2):125-135.

Rissanen, A., Sarlio-Lahteenkorva, S., Alfthan, G., Gref, C.G., Keso, L. \& Salaspuro, M. (1987). Employed problem drinkers: a nutritional risk group? Am.J.Clin Nutr 45(2):456-461.

Rodríguez-Moreno, F., González-Reimers, E., Santolaria-Fernández, F., Galindo-Martín, L., Hernandez-Torres, O., Batista-López, N., Molina-Perez, M. (1997). Zinc, copper, manganese, and iron in chronic alcoholic liver disease. Alcohol. 14(1):39-44.

Rylander, R., Megevand, Y., Lasserre, B., Amstutz, W. \& Granbom, S. (2001). Moderate alcohol consumption and urinary excretion of magnesium and calcium. Scand.J.Clin Lab Invest 61(5):401-405.

Salen, N. Jr., Olsson, N.U. (1997). Abnormalities in essential fatty acid status in alcoholism. In Handbook of Essential Fatty Acid Biology: Biochemistry, Physiology and Behavioral Neurobiology, pp. 67-87. (Anonymous). Totowa, NJ: Humana Press].

Sampson, H.W. (1997). Alcohol, osteoporosis, and bone regulating hormones. Alcohol Clin.Exp.Res. 21(3):400-403.

Schuhmacher, M., Domingo, J.L. \& Corbella, J. (1994). Zinc and copper levels in serum and urine: relationship to biological, habitual and environmental factors. Sci.Total Environ. 148(1):67-72.

Shaw, S., Jayatilleke, E., Herbert, V. \& Colman, N. (1989). Cleavage of folates during ethanol metabolism. Role of acetaldehyde/xanthine oxidase-generated superoxide. Biochem J 257(1):277-280.

Soberon, S., Pauley, M.P., Duplantier, R., Fan, A. \& Halsted, C.H. (1987). Metabolic effects of enteral formula feeding in alcoholic hepatitis. Hepatology 7(6):1204-1209.

Sonko, B.J., Prentice, A.M., Murgatroyd, P.R., Goldberg, G.R., van de Ven, M.L., Coward, W.A. (1994). Effect of alcohol on postmeal fat storage. Am J Clin Nutr. 59(3):619-625. 
Stal, P. \& Hultcrantz, R. (1993). Iron increases ethanol toxicity in rat liver. J.Hepatol. 17(1):108-115.

Stickel, F., Hoehn, B., Schuppan, D. \& Seitz, H.K. (2003). Review article: Nutritional therapy in alcoholic liver disease. Aliment.Pharmacol.Ther. 18(4):357-373.

Sullivan, J.F. (1962). Effect of alcohol on urinary zinc excretion. Q.J.Stud.Alcohol 23:216-220.

Suter, P.M. (2005). Alkohol und Ernährung. In: Alkohol und Alkoholfolgekrankheiten Grundlagen - Diagnostik - Therapie, Singer, M.V., Teyssen, S., pp. 326-348, Springer Berlin Heidelberg, ISBN 978-3-540-22552-2.

Suter, P.M., Hasler, E. \& Vetter, W. (1997). Effects of alcohol on energy metabolism and body weight regulation: is alcohol a risk factor for obesity? Nutr Rev. 55(5):157-171.

Suter, P.M., Schutz, Y. \& Jequier, E. (1992). The effect of ethanol on fat storage in healthy subjects. N.Engl.J.Med. 326(15):983-987.

Suzuki, Y., Saito, H., Suzuki, M., Hosoki, Y., Sakurai, S., Fujimoto, Y. \& Kohgo, Y. (2002). Up-regulation of transferrin receptor expression in hepatocytes by habitual alcohol drinking is implicated in hepatic iron overload in alcoholic liver disease. Alcohol Clin Exp.Res. 26(8 Suppl):26S-31S.

Tamura, T. \& Halsted, C.H. (1983). Folate turnover in chronically alcoholic monkeys. J Lab Clin.Med. 101(4):623-628.

Tanner, A.R., Bantock, I., Hinks, L., Lloyd, B., Turner, N.R. \& Wright, R. (1986). Depressed selenium and vitamin E levels in an alcoholic population. Possible relationship to hepatic injury through increased lipid peroxidation. Dig.Dis.Sci. 31(12):1307-1312.

Thomson, M., Fulton, M., Elton, R.A., Brown, S., Wood, D.A. \& Oliver, M.F. (1988). Alcohol consumption and nutrient intake in middle-aged Scottish men. Am.J Clin.Nutr 47(1):139-145.

Toniolo, P., Riboli, E. \& Cappa, A.P. (1991). A community study of alcohol consumption and dietary habits in middle-aged Italian women. Int.J Epidemiol. 20(3):663-670.

Tsukamoto, H., Horne, W., Kamimura, S., Niemela, O., Parkkila, S., Yla-Herttuala, S. \& Brittenham, G.M. (1995). Experimental liver cirrhosis induced by alcohol and iron. J.Clin Invest 96(1):620-630.

Turner, R.T., Aloia, R.C., Segel, L.D., Hannon, K.S. \& Bell, N.H. (1988). Chronic alcohol treatment results in disturbed vitamin $\mathrm{D}$ metabolism and skeletal abnormalities in rats. Alcohol Clin.Exp.Res. 12(1):159-162.

Valberg, L.S., Flanagan, P.R., Ghent, C.N. \& Chamberlain, M.J. (1985). Zinc absorption and leukocyte zinc in alcoholic and nonalcoholic cirrhosis. Dig.Dis.Sci. 30(4):329-333.

Van Haaren, M.R.T., Hendriks, H.F.J. (1999). Alkoholstoffwechsel. In: Alkohol und Alkoholfolgekrankheiten Grundlagen - Diagnostik - Therapie, Singer, M.V., Teyssen, S., pp. 95-107, Springer Berlin Heidelberg, ISBN 3-540-65094-6.

Wacker, W.E. \& Parisi, A.F. (1968b). Magnesium metabolism. N.Engl.J.Med. 278(12):658-663, 278(13):712-717, 278(14):772-776.

Watson, W.H., Song, Z., Kirpich, I.A., Deaciuc, I.V., Chen, T. \& McClain, C.J. (2011). Ethanol exposure modulates hepatic S-adenosylmethionine and S-adenosylhomocysteine levels in the isolated perfused rat liver through changes in the redox state of the NADH/NAD(+) system. Biochim.Biophys.Acta 1812(5):613-618.

World Health Organitation (WHO). (1994). Lexicon of alcohol and drug terms. [online]. Geneva, Switzerland: WHO Office of Publications; Available from: www.who.int/substance_abuse/terminology/who_lexicon/en/ 
Wood, B. , Breen, K.J. (1979). Vitamin deficiency in alcoholism with particular reference to thiamine deficiency. Clinical and Experimental pharmacology and Physiology 6:457.

Wu, A., Chanarin, I., Slavin, G. \& Levi, A.J. (1975). Folate deficiency in the alcoholic--its relationship to clinical and haematological abnormalities, liver disease and folate stores. Br.J Haematol. 29(3):469-478.

Zakhari, S. (2006). Overview: how is alcohol metabolized by the body? Alcohol Res.Health 29(4):245-254.

Zakhari, S. \& Li, T.K. (2007). Determinants of alcohol use and abuse: Impact of quantity and frequency patterns on liver disease. Hepatology 46(6):2032-2039.

Zhao, M., Matter, K., Laissue, J.A., ZimmermannA. (1996). Copper/zinc and manganese superoxide dismutases in alcoholic liver disease: immunohistochemical quantitation. Histol Histopathol. 11(4):899-907. 


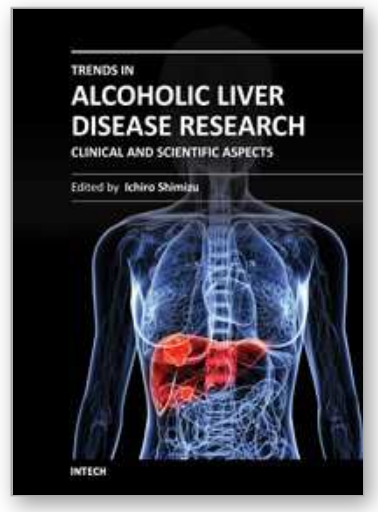

\section{Trends in Alcoholic Liver Disease Research - Clinical and Scientific Aspects}

Edited by Dr. Ichiro Shimizu

ISBN 978-953-307-985-1

Hard cover, 220 pages

Publisher InTech

Published online 11, January, 2012

Published in print edition January, 2012

Alcoholic liver disease occurs after prolonged heavy drinking. Not everyone who drinks alcohol in excess develops serious forms of alcoholic liver disease. It is likely that genetic factors determine this individual susceptibility, and a family history of chronic liver disease may indicate a higher risk. Other factors include being overweight and iron overload. This book presents state-of-the-art information summarizing the current understanding of a range of alcoholic liver diseases. It is hoped that the target readers - hepatologists, clinicians, researchers and academicians - will be afforded new ideas and exposed to subjects well beyond their own scientific disciplines. Additionally, students and those who wish to increase their knowledge will find this book a valuable source of information.

\section{How to reference}

In order to correctly reference this scholarly work, feel free to copy and paste the following:

Sabine Wagnerberger, Giridhar Kanuri and Ina Bergheim (2012). Alcohol Drinking Patterns and Nutrition in Alcoholic Liver Disease, Trends in Alcoholic Liver Disease Research - Clinical and Scientific Aspects, Dr. Ichiro Shimizu (Ed.), ISBN: 978-953-307-985-1, InTech, Available from: http://www.intechopen.com/books/trends-inalcoholic-liver-disease-research-clinical-and-scientific-aspects/alcohol-drinking-patterns-and-nutrition-inalcoholic-liver-disease

\section{INTECH}

open science | open minds

\author{
InTech Europe \\ University Campus STeP Ri \\ Slavka Krautzeka 83/A \\ 51000 Rijeka, Croatia \\ Phone: +385 (51) 770447 \\ Fax: +385 (51) 686166 \\ www.intechopen.com
}

\author{
InTech China \\ Unit 405, Office Block, Hotel Equatorial Shanghai \\ No.65, Yan An Road (West), Shanghai, 200040, China \\ 中国上海市延安西路65号上海国际贵都大饭店办公楼 405 单元 \\ Phone: +86-21-62489820 \\ Fax: $+86-21-62489821$
}


(C) 2012 The Author(s). Licensee IntechOpen. This is an open access article distributed under the terms of the Creative Commons Attribution 3.0 License, which permits unrestricted use, distribution, and reproduction in any medium, provided the original work is properly cited. 